\title{
Does Action vs. State Orientation Really Matter in the Susceptibility to Sunk Cost Fallacy? A Conceptual Replication Study
}

Miroslava Galasová (D), Matúš Grežo iD

Institute of Experimental Psychology, Centre of Social and Psychological Sciences, Slovak Academy of Sciences, Bratislava, Slovak Republic

The theory of action versus state orientation suggests that state-oriented people are more susceptible to sunk cost fallacy than action-oriented people because they ruminate about past costs and are reluctant to change their course of actions. However, research on the role of action versus state orientation in sunk cost fallacy is fairly limited. Therefore, the present paper aims to conceptually replicate the seminal study by van Putten et al. (2010) and verify whether action versus state orientation really matters in the susceptibility to sunk cost fallacy. We also examined the role of gender and goal internalization in the susceptibility to sunk cost fallacy. Participants $(N=205)$ filled an Action Control Scale and solved two sunk cost fallacy tasks in two experimental conditions. In the intrapersonal condition, the sunk costs belonged to a decision-maker. In the intrapersonal condition, an investor was not identical with the decision-maker. Eventually, our study failed to replicate the results of van Putten et al. (2010). Action versus state orientation did not predict the susceptibility to sunk cost fallacy. Moreover, neither gender nor internalization moderated the relationship between action versus state orientation and susceptibility to sunk cost fallacy. We suggest further replications to examine the roles of reluctance to change and rumination in the relationship between action versus state orientation and susceptibility to sunk cost fallacy. Our findings also highlight the importance of high-powered replications that are an essential part of good research practice.

Key words: sunk cost fallacy, action vs. state orientation, internalization, gender differences, rumination

The sunk cost fallacy (SCF) is a widely studied cognitive bias that describes the behavior of people who invest additional resources into a failing activity just because they have already invested a lot in it. However, from the perspective of normative decision-making

\footnotetext{
Correspondence concerning this article should be addressed to Miroslava Galasová, Institute of Experimental Psychology, Centre of Social and Psychological Sciences, Slovak Academy of Sciences, Dúbravská cesta 9, 84104 Bratislava, Slovak Republic. E-mail: miroslava.galasova@savba.sk Supplementary material to this paper is available at https://journals.savba.sk/index.php/studiapsychologica/article/view/238
}

Received September 27, 2020 
theories, when deciding about continuing in a failing activity, individuals should ignore past costs. Yet, the literature shows that people often do not follow this prescription and take on additional costs just to prevent wasting earlier investments (Kelly, 2004). The meta-analytic review by Roth et al. (2014) showed that SCF is a robust phenomenon, but its strength varies across specific situational contexts and individual factors. The present study focuses on one of these individual factors, the action vs. state orientation, which represents the ability of individuals to regulate their emotions, be proactive, and persist in started tasks.

The effect of action vs. state orientation on the susceptibility to SCF was presented in the seminal paper by van Putten et al. (2010), who showed that state-oriented individuals were more susceptible to SCF than action-oriented individuals. One possible reason is that state-oriented people tend to ruminate about the failure, and therefore, they see the current investment decision "in the light of previous investments" (p. 33). However, despite their indubitable contribution, we identified several methodological issues in the study of van Putten et al. (2010) that led us to further verification and extension of the study. We, first, conceptually replicated the research by van Putten et al. (2010) to verify whether action vs. state orientation predicts susceptibility to the SCF. Second, reflecting on the inconclusive findings on the gender differences in the current SCF literature, we extended their study by examining gender as a moderator of the relationship between action vs. state orientation and susceptibility to the SCF. Third and last, a degree to which individuals internalize beliefs, wishes, and expectations of others might relate to action vs. state orientation (Kuhl, 1992). Therefore, we extended van Putten et al.'s (2010) study using both intrapersonal and interpersonal types of sunk cost situations (Olivola, 2018).

\section{Theoretical Background}

\section{The Conceptualization of Sunk Costs Fallacy}

According to the economic theory, sunk costs are costs that cannot be recovered by any means, no matter how the individual decides to act. Therefore, such costs "can and should be ignored” (Kelly, p. 72). Our actual behavior, however, often violates this rational prescription, and people usually take sunk costs into account. This tendency is called the sunk cost fallacy (SCF). SCF is often defined as the general tendency for people to continue in an inferior activity or pursuing an inferior option just because they have already invested resources in it (Olivola, 2018). Importantly, the "fallacy aspect" lies in the fact that one would choose a better option if he or she would not have previously invested resources in an inferior option.

Following the seminal paper by Arkes and Blumer (1985), the SCF phenomenon has been studied through various tasks and situations. This included comparing different types of sunk cost situations like money, time, or effort (e.g., Tait \& Miller, 2019) and different bearers of the sunk costs (e.g., Olivola, 2018). Other studies have also examined how SCF appears in different cultures (Yoder et al., 2014) or how individual differences like age or personality traits shape the occurrence of SCF (Bruine de Bruin et al., 2014; Fujino et al., 2016). The meta-analytic review of 98 effect sizes of the sunk cost effects by Roth et al. (2014) showed that SCF is a robust phenomenon, but its effect size varies across specific situational contexts and individual factors. Van Putten et al. (2010) suggest that one of these influential individual factors is action versus state orientation. 


\section{Action vs. State Orientation and Sunk Cost Fallacy}

The concept of the action versus state orientation was introduced by Kuhl (1994) to indicate an ability to initiate an action and sustain it until the end. According to the action control theory (see Kuhl, 2000), the reaction of individuals to difficult decision-making depends on whether they are in a metastatic, change-promoting mode or a catastatic, change-preventing regulatory mode. In the former, individuals are decisive, and they actively pursue intentional action. In the latter, individuals struggle in the decision process, and they are hesitant to change their mental and behavioral states. Notably, according to Kuhl (1994), individuals systematically differ in their tendency to use change-promoting or change-preventing mode. This stable tendency is known as action versus state orientation.

Besides decisiveness and proactivity, action vs. state orientation also relates to an individual ability to regulate emotions during the decision process (Kuhl \& Beckmann, 1994). Specifically, a type of orientation indicates whether individuals cling to past events or get over negative situations quickly. In general, action-oriented individuals are better at regulating their affective states (Kazén et al., 2003; Koole \& Jostmann, 2004; Jostmann et al., 2005). State-oriented individuals, on the other hand, tend to reflect and ruminate about past events and decisions more than action-oriented individuals, and this blocks them from commencing further actions.

For assessing differences between actionand state-oriented individuals, Kuhl (1994) designed the Action-Control Scale (ACS), consisting of three subscales - preoccupation, hesitation, and volition. The preoccupation subscale indicates whether people can focus on a relevant goal and disengage from poten- tial negative situations that happened in the past or recently. Action-oriented individuals usually do not ruminate about unpleasant experiences, while state-oriented individuals find it difficult to disengage from these situations. Second, the hesitation subscale indicates either initiative behavior among action-oriented individuals or a slower and more hesitative approach towards new tasks among state-oriented individuals. Finally, the volatility subscale represents how much an individual can persist in a current activity without distractions or pauses. Action-oriented individuals show higher persistence in tasks in progress, whereas state-oriented individuals tend to interrupt started activities frequently (Diefendorff et al., 2000).

Concerning the relationship between action vs. state orientation and SCF, van Putten et al. (2010) hypothesized that individual differences in action vs. state orientation could affect the susceptibility of individuals to SCF. They conducted a study using both SCF and non-SCF scenarios and investigated how action- and state-oriented individuals decide about the investment in the failing project. They found that action-oriented participants in SCF and non-SCF conditions did not significantly differ in their willingness to continue in the failing project. However, this was not true for the state-oriented individuals who were substantially more willing to continue in the project than action-oriented people in the SCF condition but not in the non-SCF condition. More importantly, when comparing action- vs. state-oriented individuals in the SCF condition, van Putten et al. (2010, p. 35) concluded that they found a "marginally significant $(p=0.08)$ " difference between action- and state-oriented individuals in the susceptibility to SCF, with action-oriented individuals being less susceptible. Nonetheless, this difference was, technically speaking, insignificant although they interpreted it as a 
positive discovery.

The study by van Putten et al. (2010) brought an interesting view on how individual differences in action vs. state orientation could affect one's susceptibility to SCF. However, although Bruine de Bruin et al. (2014) addressed a very similar area of the relationships between rumination and susceptibility to SCF, we have not found any further studies that would verify the results of van Putten et al. (2010). Moreover, we also see other reasons for conducting further studies on this matter. Most notably, the research sample in the study by van Putten et al. (2010) consisted of only seventy-five students. Such a limited number of participants might raise questions about the generalizability of the findings because of the low statistical power. As Button et al. (2013) state, low statistical power of a study can be responsible for three main problems: 1) a low probability of finding true effects (i.e., producing more false-negative findings), 2) a low positive predictive value when an effect is claimed, and 3) exaggerated estimate of the magnitude of the effect when a true effect is discovered.

Considering these possible problems within the study by van Putten et al. (2010), it is very hard to estimate whether a significant difference between action- and state-oriented individuals could be achieved by using a larger sample size. Therefore, our first aim was to conceptually replicate the main findings of van Putten et al. (2010) on the effect of action vs. state orientation on the susceptibility to SCF. Following their findings, we hypothesized that:

H1: The more action-oriented individuals are, the less susceptibility to SCF they manifest.

\section{Gender Differences in the Sunk Cost Fallacy}

Considering the emotion regulation aspect of the action vs. state orientation character- istic, the unbalanced number of women and men participating in the research sample in the study of van Putten et al. (2010) might be problematic. Specifically, men created only $17 \%(13)$ of the whole research sample ( $N=$ 75). A meta-analysis by Johnson and Whisman (2013) shows that women, compared to men, have a greater tendency to ruminate, brood, and reflect on their previous decisions and experiences. Importantly, the tendency to ruminate fosters the need to continue investing resources in failing events (Bruine de Bruin et al., 2014). Thus, when van Putten et al. (2010) concluded that there was a difference in the susceptibility to SCF between action- and state-oriented individuals, who tend to ruminate about failures more, this difference could have been caused by the prevailing number of women in the study. In other words, if the research sample had included more state-oriented men, the indirect support of women's rumination about sunk costs could have been much lower.

Our hypothesizing highlights the importance of verifying the findings of van Putten et al. (2010) on a larger population, including more men. This could be especially important given the fact that current literature is not conclusive about gender differences in the susceptibility to SCF. Specifically, two studies found women more susceptible to SCF than men (Bavolar, 2013; Liang \& Zou, 2018). The studies, however, did not use SCF scenarios but observed the resistance to the sunk costs using the Adult Decision-Making Competence scale. Except for these, several papers are reporting no significant gender differences (Laing, 2002; Falchetta, 2015; Keil et al., 2011; Ronayne et al., 2020) or even mixed results with both women and men being more susceptible to SCF according to the specific SCF scenarios (Richardson, 2011).

In addition to pointing out the inconclusiveness in the current literature, it is important 
to note that there is a lack of systematic studies on gender differences in the SCF because most studies used gender only as a control variable. Therefore, we aim to examine how gender interacts with the action vs. state orientation in the sunk cost decision-making. Considering our suggestion about the possible effect of rumination on SCF, we hypothesize that:

$H 2$ : Gender moderates the relationship between action vs. state orientation and the susceptibility to SCF.

\section{Internalization in Relation to Action vs. State Orientation and Sunk Cost Fallacy}

Finally, our study addresses the last possible interfering aspect that was present in the study by van Putten et al. (2010). Specifically, the decision-maker in the SCF scenario was a bearer of the idea of investment, who invested a certain amount of resources in a failing project and decided about further investment. In the non-SCF scenario, however, the decision-maker did not make any previous investments and, importantly, has received the suggestion to further invest from one of the company employees. Obviously, the two scenarios did not differ only in the presence of sunk costs but also in the aspect of who brought the idea of future investment. This led us to speculate that the slight difference in the scenarios could have affected the personal commitment to further investing.

Personal commitment appeared to be a vital aspect explaining susceptibility to SCF (Arkes \& Blumer, 1985; Schulz \& Cheng, 2002; Staw, 1976). Moreover, studies show significant differences in how action- and state-oriented individuals feel committed to following the goals and suggestions of others (e.g., Kazén et al., 2003; Shi et al., 2018; Wolf et al., 2018). For example, Kuhl (1992) pointed out that individuals high in state orientation have a greater tendency to internalize others' beliefs, wishes, and expectations. Thus, the state-oriented participants in the study of van Putten et al. (2010) could have internalized the suggestion of the employee, which affected their decision-making. This is in line with Kazén et al. (2003), who observed that state-oriented people exposed to negative affect or stress were not as effective in resisting external effects as action-oriented people. As a result, a potential internalization in the study of van Putten et al. (2010) could have caused the fact that they did not find significant differences in the willingness to invest in a project between action- and state-oriented participants in the non-SCF scenario.

To explore this possible effect, we aim to experimentally examine how the susceptibility to SCF for action- and state-oriented individuals differs in situations that do and do not evoke internalization of goals of another person. Since this is the first attempt to combine the internalization manipulation, action vs. state orientation, and the susceptibility to SCF, we formulate the following research question:

$R Q 1:$ Does the relationship between action vs. state orientation and the susceptibility to SCF depend on the type of SCF scenario (internalization evoking vs. not evoking internalization)?

\section{Methods}

\section{Participants}

We used a rule of thumb to assess the size of the sample - at least 100 participants per group. We had two groups - one with intrapersonal and one with interpersonal sunk cost, and thus, the expected number of responses was 200. We collected answers from 214 participants via snowball sampling. Their participation was voluntary, and they did not 
receive any financial reward. Due to incorrect responses to the control question ${ }^{1}$, we excluded 9 participants. Thus, our final sample consisted of 205 participants (150 women - 73\%, 53 men - 26\%, 2 other - 1\%). Age of the participants varied from 18 to $65(M=$ 27.29, $S D=9.62$ ). A small number of participants (3.4\%) achieved elementary education, and the same percentage was represented by participants with high school education without the final examination. Most of the participants finished higher education with a final examination (45.85\%). A similar portion (47.35\%) obtained a university degree (bachelor $-33.65 \%$, master $-12.7 \%$, doctoral $-1 \%$ ).

\section{Procedure and Design}

The research was conducted via an online questionnaire designed on the Qualtrics platform. Participants were informed about the purpose of the research at the beginning of the questionnaire. After agreeing with the conditions, they first answered several socio-demographic questions and 36 items measuring their action-state orientation. Then, they were exposed to a simple experimental design in which they were randomly assigned to one of the two conditions by which we manipulated the internalization. In the first condition, they solved two hypothetical in trapersonal sunk cost scenarios, in which the sunk costs were borne by the decision-maker. In the second condition, they solved two interpersonal sunk cost scenarios, where the bearer of the sunk costs was someone else. Scenarios in both conditions were presented randomly to prevent the task order effect.

${ }^{1}$ The instruction of the control question might have been misleading. Even though the instruction led participants to "answer by option \#3", the majority responded by choosing option \#4 (189 participants). Therefore, we decided to include both, those who answered by option \#4 or option \#3 (16 participants) and excluded all who answered \#1, \#2, or \#5 (9 participants).

\section{Materials}

\section{Sunk Cost Fallacy scenarios}

We conducted two pilot studies $\left(N_{1}=21\right.$; $N_{2}=28$ ) to test eight hypothetical SCF scenarios that proved to be effective in previous studies (i.e., Arkes \& Blumer, 1985; Olivola, 2018). In the pilots, participants indicated how much they were willing to continue in the commenced activity from 0 (definitely will not continue) to 9 (definitely will continue). Then, we calculated the mean values of responses in the scenarios. If the value was above four, it meant that the scenario was effective in inducing the SCF. For the current study, we picked the two most effective SCF scenarios that elicited the sunk cost fallacy the most. However, for the current study, we used an 11-point scale ranging from 0 (definitely will not continue) to 10 (definitely will continue).

In the first scenario (SCF_Car), participants were asked to imagine they were the owners of a car company that was about to invest in a new project (inspired by Arkes \& Blumer, 1985). They had two options - either invest in developing a new electric car or invest in developing a hydrogen car. They have chosen to invest in an electric car with a vision to be the leader in the market. After some time, when $70 \%$ of resources have been invested, they found out that a competing company introduced a new electric car that was cheaper, and its battery lasted more than their future model. It was clear that the company of participants would not be the leader in the market anymore. The task for the participants was to decide whether they wanted to invest further money in the project or terminate it.

In the second scenario (SCF_Concert), participants decided about whether to go to a concert by their favorite singer. Unfortunate- 
ly, the attendance at this concert could have serious, even hazardous consequences due to dangerous weather conditions (Olivola, 2018). Participants already had a ticket that was not cheap, and they had to decide to either risk their health and attend the concert or stay safe at home.

\section{Internalization Manipulation}

Inspired by Olivola (2018), who measured differences in intrapersonal and interpersonal sunk costs, we created two versions of the scenarios. Through them, we manipulated the information about the investor to induce internalization. In the intrapersonal scenarios, the invested resources in the concert or the car project belonged to the decision-maker. Thus, there was no internalization and the participants were the investors as well as decision-makers. In the interpersonal scenarios, the invested resources belonged to a friend of the decision-maker or a sleeping partner ${ }^{2}$ in a car company. In this condition, we induced internalization through an investor who was not identical to the decision-maker. Participants had to decide how much they were willing to continue in the started activity on a 11-point Likert scale ( 0 - I definitely will not go/invest; 10 - I definitely will go/invest). Values above five indicate that participants fall prey to sunk cost fallacy.

\section{Action Control Scale (ACS)}

The ACS is a self-report scale originally developed by Kuhl (1994), which assesses an action or a state orientation of a person (Diefendorff et al., 2000; Kuhl \& Beckmann, 1994). The scale consists of three subscales - preoccupation, hesitation, and volatility. Each of the

\footnotetext{
${ }^{2}$ A sleeping partner is a person in a company who provides a part of the financial or other resources but does not actively participate in managing the company.
}

subscales contains 12 items to which participants answer by two statements representing two poles. The preoccupation subscale has two poles - preoccupation and disengagement (e.g., When something really gets me down: A. I have trouble doing anything at all; $B$. I find it easy to distract myself by doing other things). Poles of the hesitation subscale are hesitation and initiative (e.g., When I know I must finish something soon: A. I have to push myself to get started; $B$. I find it easy to get it done and over with). Finally, the volatility subscale has two poles of volatility and persistence (e.g., When I am busy working on an interesting project: $A$. I need to take frequent breaks and work on other projects; B. I can keep working on the same project for a long time).

In the original version, participants got 1 or 0 points based on the chosen statement, which could indicate action-oriented or state-oriented behavior. We have decided to use the 5-point Likert scale instead of the original setup based on two options. Therefore, one statement lying at the beginning of the scale was denoted as 0 , and the second option lying on the opposite end was denoted by 4 . As in the original scale, low scores indicate state orientation, and higher scores imply action orientation. Despite the changes, the overall reliability of the ACS scale was good $(\omega=$ .81). The reliability was also good for the two subscales preoccupation $(\omega=.82)$ and hesitation $(\omega=.79)$. The subscale volatility had lower reliability $(\omega=.70)$ but still acceptable. According to Diefendorff et al. (2000), the lower reliability of the volatility subscale can be explained by various studies that see this subscale as a different construct. Nevertheless, working with the ACS scale with a single factor or three-factor model is still possible (Diefendorff et al., 2000; Kuhl, 1994). Therefore, we have decided to use a three-factor model with all three ACS subscales. 


\section{Results}

\section{Descriptive Statistics}

For future replications or meta-analytical studies, Table 1 reports descriptive statistics and a correlation matrix for our study variables. For the action vs. state orientation measure, we report the data for the whole ACS scale as well as specific subscales. In line with previous studies questioning the dimensionality of the ACS scale (Diefendorff et al., 2000), our data show that the volatility subscale correlated weakly with the other two subscales. Moreover, it correlated negatively with preoccupation but positively with hesitation subscale. Due to this, we have decided not to use one joint ACS score in our analyses but instead examine the three subscales separately. The correlation analysis also showed that the two SCF scenarios did not significantly correlate, suggesting that they should be treated independently in further analyses. Therefore, we tested our hypotheses for each SCF scenario separately.

\section{The Effect of Action Orientation on Suscepti- bility to SCF}

We hypothesized that the more state-oriented individuals are, the more susceptible they will be to SCF. Therefore, we used multiple linear regression to test whether the three subscales of ACS predict the susceptibility to SCF in the Car and Concert scenario separately. The results indicated that the model was not significant either for the Car scenario $\left(R^{2}=\right.$ $.01, F(3,201)=.38, p=.77)$ or for the Concert scenario $\left(R^{2}<.01, F(3,201)=.32, p=.81\right)$. The three subscales explained only negligible variance of the susceptibility to SCF. Table 2 shows that none of the three subscales significantly predicted susceptibility to SCF in two scenarios.

\section{Gender as a Moderator of the Relationship between Action Orientation and Susceptibil- ity to SCF}

We aimed to examine the moderating effect of gender on the relationship between action vs. state orientation and susceptibility to SCF. Before testing the moderating effect, we examined the difference in susceptibility to SCF between women and men. Due to the deviation from normality, we have decided to use Welch's independent samples $t$-test. The analysis showed significant gender difference in susceptibility to SCF for the Car scenario ( $t=2.19, p=.03$, Cohen's $d=.34,95 \% \mathrm{Cl}[.08$, 1.63]), with men ( $M=6.32, S D=2.41)$ achieving higher mean score than women $(M=5.47$, $S D=2.53)$. For the Concert scenario, Welch's

Table 1 Descriptive statistics and correlation matrix

\begin{tabular}{lrrrrrrrr}
\hline & \multicolumn{1}{c}{ M } & \multicolumn{1}{c}{ SD } & 1 & 2 & 3 & 4 & 5 & 6 \\
\hline 1. Age & 27.29 & 9.62 & & & & & & \\
2. ACS_Preoccupation & 2.71 & .68 & $.27^{* *}$ & & & & & \\
3. ACS_Hesitation & 3.01 & .48 & .26 & $.35^{* *}$ & & & & \\
4. ACS_Volatility & 3.89 & .54 & -.18 & $-.16^{*}$ & $.19^{* *}$ & & & \\
5. ACS_Overall & 3.20 & .37 & .20 & $.70^{* *}$ & $.75^{* *}$ & $.48^{* *}$ & & \\
6. SCF_Car & 5.66 & 2.53 & .06 & -.06 & -.04 & .04 & -.03 & \\
7. SCF_Concert & 6.39 & 3.10 & -.09 & -.05 & -.02 & -.03 & -.06 & .08 \\
\hline
\end{tabular}

Note. ${ }^{*} p<.05,{ }^{* *} p<.01$ 
Table 2 Regression of three ACS subscales on susceptibility to SCF in two scenarios

\begin{tabular}{llcccccc}
\hline Model & Predictor & $b$ & $S E$ & $b$ & $t$ & $p$ & $95 \% \mathrm{Cl}[\mathrm{LL}, \mathrm{UL}]$ \\
\hline SCF_Car & Preoccupation & -.12 & .29 & -.03 & -.43 & .67 & {$[-.69, .44]$} \\
& Hesitation & -.21 & .41 & -.04 & -.52 & .60 & {$[-1.02, .59]$} \\
& Volatility & .21 & .34 & .05 & .62 & .53 & {$[-.46, .89]$} \\
& & & & & & & \\
SCF_Concert & Preoccupation & -.29 & .35 & -.06 & -.83 & .41 & {$[-.99, .40]$} \\
& Hesitation & .09 & .50 & .01 & .18 & .86 & {$[-.90,1.07]$} \\
& Volatility & -.26 & .42 & -.05 & -.62 & .54 & {$[-1.09, .57]$} \\
\hline
\end{tabular}

Note. $N=205, b$ represents unstandardized regression weights, LL and UL indicate the lower and upper limits of a $95 \%$ confidence interval for unstandardized regression coefficients.

Table 3 Gender as a moderator of the relationship between action vs. state orientation subscales and susceptibility to SCF

\begin{tabular}{|c|c|c|c|c|c|c|c|c|c|}
\hline Criterion & Predictor & $b$ & $S E$ & $p$ & $95 \% \mathrm{Cl}[\mathrm{LL}, \mathrm{UL}]$ & $R^{2}$ & ${ }_{\Delta} R^{2}$ & $F$ & $p$ \\
\hline Susceptibility & & & & & & .03 & .00 & .09 & .76 \\
\hline to SCF in the & Preoccupation & -.03 & 1.08 & .98 & {$[-2.17,2.11]$} & & & & \\
\hline \multirow[t]{10}{*}{ car scenario } & Gender & -.47 & 1.80 & .80 & {$[-4.02,3.09]$} & & & & \\
\hline & Interaction & -.18 & .61 & .76 & {$[-1.38,1.01]$} & & & & \\
\hline & & & & & & .03 & .00 & .47 & .50 \\
\hline & Hesitation & .91 & 1.67 & .59 & {$[-2.39,4.21]$} & & & & \\
\hline & Gender & 1.02 & 2.81 & .72 & {$[-4.51,6.56]$} & & & & \\
\hline & Interaction & -.62 & .91 & .50 & {$[-2.42,1.17]$} & & & & \\
\hline & & & & & & .03 & .00 & .70 & .41 \\
\hline & Volatility & 1.23 & 1.23 & .32 & {$[-1.20,3.66]$} & & & & \\
\hline & Gender & 1.38 & 2.73 & .61 & {$[-4.01,6.77]$} & & & & \\
\hline & Interaction & -.59 & .70 & .41 & {$[-1.97, .80]$} & & & & \\
\hline Susceptibility & & & & & & .02 & .00 & .94 & .33 \\
\hline to SCF in the & Preoccupation & .84 & 1.34 & .53 & {$[-1.79,3.48]$} & & & & \\
\hline concert & Gender & 1.24 & 2.22 & .58 & {$[-3.15,5.62]$} & & & & \\
\hline \multirow[t]{9}{*}{ scenario } & Interaction & -.72 & .75 & .33 & {$[-2.19, .75]$} & & & & \\
\hline & & & & & & .01 & .00 & .05 & .83 \\
\hline & Hesitation & .21 & 2.07 & .92 & {$[-3.87,4.28]$} & & & & \\
\hline & Gender & .04 & 3.47 & .99 & {$[-6.79,6.88]$} & & & & \\
\hline & Interaction & -.25 & 1.12 & .83 & {$[-2.46,1.97]$} & & & & \\
\hline & & & & & & .01 & .00 & .20 & .66 \\
\hline & Volatility & .52 & 1.53 & .73 & {$[-2.49,3.53]$} & & & & \\
\hline & Gender & .82 & 3.38 & .81 & {$[-5.85,7.49]$} & & & & \\
\hline & Interaction & -.39 & .87 & .66 & {$[-2.10,1.33]$} & & & & \\
\hline
\end{tabular}

Note. $N=205, b$ represents unstandardized regression weights, LL and UL indicate the lower and upper limits of a $95 \%$ confidence interval for unstandardized regression coefficients, $R^{2}$ indicates the explained variance of two predictors without including interaction, $\triangle R^{2}, F$, and $p$ statistics reflect the change in the model due to interaction. 
t-test showed no significant gender difference ( $t=1.39, p=.17$, Cohen's $d=.22,95 \% \mathrm{Cl}[-.30$, 1.67]), despite men $(M=6.89, S D=3.10)$ achieving higher mean score than women ( $M=6.20, S D=3.08$ ).

For the investigation of the moderating effect of gender on the relationship between action vs. state orientation and susceptibility to SCF, we used PROCESS macro for SPSS proposed by Preacher and Hayes (2004) with 5,000 bootstrap samples and $95 \%$ bias-corrected Cls. We performed the analysis for each SCF scenario separately. To determine a moderating effect, the interaction terms had to show a statistically significant amount of variance explained for susceptibility to SCF, with a $95 \%$ confidence interval not containing a zero (Hayes \& Rockwood, 2017).

The results showed that the relationship between three ACS subscales and susceptibility to SCF was not significantly moderated by gender, and this was found in both Car and Concert scenarios (Table 3). Specifically, in each analysis the two predictors accounted for only negligible variation in susceptibility to SCF, and adding the interaction did not result in a significant change in the model. The effects of interactions were not significant in all

Table 4 The type of scenario as a moderator of the relationship between the three action vs. state orientation subscales and susceptibility to SCF

\begin{tabular}{|c|c|c|c|c|c|c|c|c|c|}
\hline Criterion & Predictor & $b$ & $S E$ & $p$ & 95\% Cl [LL, UL] & $R^{2}$ & ${ }_{\Delta} R^{2}$ & $F$ & $p$ \\
\hline Susceptibility & & & & & & .01 & .01 & 1.16 & .28 \\
\hline to SCF in the & Preoccupation & -1.05 & .83 & .21 & {$[-2.69, .59]$} & & & & \\
\hline \multirow{10}{*}{ car scenario } & Type of scenario & -1.48 & 1.45 & .31 & {$[-4.35,1.38]$} & & & & \\
\hline & Interaction & .56 & .52 & .28 & {$[-.47,1.59]$} & & & & \\
\hline & & & & & & .00 & .00 & .33 & .56 \\
\hline & Hesitation & -.85 & 1.13 & .45 & {$[-3.09,1.38]$} & & & & \\
\hline & Type of scenario & -1.25 & 2.28 & .58 & {$[-5.75,3.25]$} & & & & \\
\hline & Interaction & .43 & .75 & .56 & {$[-1.04,1.91]$} & & & & \\
\hline & & & & & & .00 & .00 & .07 & .79 \\
\hline & Volatility & .47 & 1.05 & .65 & {$[-1.59,2.54]$} & & & & \\
\hline & Type of scenario & .70 & 2.59 & .79 & {$[-4.41,5.81]$} & & & & \\
\hline & Interaction & -.18 & .66 & .79 & {$[-1.48,1.12]$} & & & & \\
\hline Susceptibility & & & & & & .01 & .00 & .09 & .76 \\
\hline to SCF in the & Preoccupation & .05 & 1.01 & .96 & {$[-1.95,2.05]$} & & & & \\
\hline concert & Type of scenario & 1.08 & 1.77 & .54 & {$[-2.42,4.58]$} & & & & \\
\hline \multirow[t]{9}{*}{ scenario } & Interaction & -.20 & .64 & .76 & {$[-1.45,1.06]$} & & & & \\
\hline & & & & & & .01 & .00 & .22 & .64 \\
\hline & Hesitation & .44 & 1.38 & .75 & {$[-2.29,3.17]$} & & & & \\
\hline & Type of scenario & 1.84 & 2.78 & .51 & {$[-3.65,7.33]$} & & & & \\
\hline & Interaction & -.43 & .91 & .64 & {$[-2.22,1.37]$} & & & & \\
\hline & & & & & & .01 & .00 & .76 & .39 \\
\hline & Volatility & .80 & 1.27 & .53 & {$[-1.71,3.31]$} & & & & \\
\hline & Type of scenario & 3.29 & 3.15 & .30 & {$[-2.92,9.50]$} & & & & \\
\hline & Interaction & -.70 & .80 & .39 & {$[-2.28, .89]$} & & & & \\
\hline
\end{tabular}

Note. $N=205, b$ represents unstandardized regression weights, LL and UL indicate the lower and upper limits of a $95 \%$ confidence interval for unstandardized regression coefficients, $R^{2}$ indicates the explained variance of two predictors without including interaction, $\triangle R^{2}, F$, and $p$ statistics reflect the change in the model due to interaction. 
analyses, clearly suggesting that gender did not moderate the relationship between ACS subscales and susceptibility to SCF.

Intrapersonal vs. Interpersonal Type of SCF Scenario as a Moderator of the Relationship between Action Orientation and Susceptibility to SCF

Finally, we were interested whether the relationship between action vs. state orientation and susceptibility to SCF depends on internalization. Firstly, we examined whether individuals manifested a different susceptibility to SCF in intrapersonal and interpersonal SCF scenarios. As in previous gender analysis, due to the deviation from normality, we have decided to use Welch's independent samples $t$-test. The analysis showed no significant difference $(t=.08, p=.94$, Cohen's $d=.01,95 \%$ $\mathrm{Cl}[-.72, .67])$ in susceptibility to SCF between intrapersonal $(M=5.68, S D=2.71)$ and interpersonal $(M=5.65, S D=2.32)$ Car scenario. $A$ very similar result was found for the Concert scenario. Welch's $t$-test showed no significant gender difference $(t=1.26, p=.21$, Cohen's $d=.18,95 \% \mathrm{Cl}[-1.40, .31])$ between intrapersonal $(M=6.65, S D=3.03)$ and interpersonal condition $(M=6.10, S D=3.15)$.

Using moderation analysis with 5,000 bootstrap samples and $95 \%$ bias-corrected $\mathrm{Cl}$ s in the next step, we examined whether the effect of action vs. state orientation on susceptibility to SCF varies depending to the two types of SCF scenarios (interpersonal and intrapersonal). The results showed that the effects of the three specific ACS subscales on susceptibility to SCF were not significantly moderated by the type of scenario. This was found both for the Car and Concert scenarios (Table 4). Similar to the previous gender analyses, the two predictors in each model accounted for only negligible variation in susceptibility to SCF. Adding the interactions did not result in significant changes in the models. The interactions were not significant in all analyses, suggesting that the effect of action vs. state orientation on susceptibility to SCF was not dependent on whether the SCF scenario was intrapersonal or interpersonal.

\section{Discussion}

Sunk cost fallacy is a robust phenomenon in which individual differences can play a role. Action vs. state orientation, an individual difference that indicates whether a person is prochange (action-oriented) or against change (state-oriented), seemed to affect susceptibility to SCF in the study of van Putten et al. (2010). The goal of the present study, thus, was to conceptually replicate the study of van Putten et al. (2010) and address three issues that, as we believed, could have affected their results.

The first issue of the van Putten et al. (2010) study lied in the low number of participants in the research sample. In addition, the authors decreased the sample size by using only those participants who scored one standard deviation above and below the mean in the action vs. state orientation. This might have caused that the analyses with such a very limited sample size were more sensitive to outliers and less sensitive to detect the true effect. Hence, we almost tripled the number of participants. We also treated the action vs. state orientation as a continuous variable instead of splitting and reducing the research sample according to one standard deviation above and below the average score. Consequently, with such an increase in the number of participants, we did not find any support for our first hypothesis, in which we expected that higher action orientation would lead to lower susceptibility to SCF. Eventually, we failed to conceptually replicate the main finding of van Putten et al. (2010). Nevertheless, we recom- 
mend further replication studies to examine whether this inconsistency lies in the limited statistical power of the original study (Button et al., 2013).

The second issue we addressed was the greatly prevailing number of women in the original study. Specifically, the authors concluded that the significant difference between action- and state-oriented individuals could be caused by a greater tendency of state-oriented people to ruminate about failure. If their interpretation was correct, then the greater tendency to ruminate of state-oriented individuals could be fostered by an excessive number of women who, in general, tend to ruminate more (Johnson \& Whisman, 2013). Yet, although we increased the proportion of men in the sample, our hypothesis about gender moderating the relationship between the action vs. state orientation and susceptibility to SCF was not supported.

We did, however, find a significant difference between men and women in the SCF car scenario, irrespective of action vs. state orientation. Interestingly, despite the more ruminative "nature" of women, who were supposed to ruminate about the past costs, and thus, be more susceptible to SCF, men were those who were more willing to invest in the failing project. Rumination did not play a role in our study then. On the other hand, we speculated that the difference in susceptibility to SCF between action- and state-oriented individuals in van Putten et al.'s (2010) study could lie in the reluctance of state-oriented individuals to change the course of action (Kuhl, 1994).

Specifically, in the SCF scenario, state-oriented individuals could have kept the status-quo by continuing investing in the failing activity, and so they did. In the non-SCF scenario, the state-oriented individuals could have kept the status quo by not starting any investment, and thus, they were less motivated to invest. This tendency to "stick to the previous behavior" could be, in fact, more responsible for the findings of van Putten et al. (2010) than the gender-dependent ruminative tendencies. Finally, although the moderation effect of gender was not supported in our study, an important note is that our findings suggest that gender can affect susceptibility to SCF independently of the action vs. state orientation. In general, however, our findings contribute to the section of mixed gender results in SCF with no gender difference in SCF (e.g., Falchetta, 2015; Keil et al. 2011) and with men being more susceptible to SCF (Richardson, 2011).

The third problematic point that we aimed to address in the study of van Putten et al. (2010) was the slight difference between SCF and non-SCF scenarios. Instead of having a decision-maker being the bearer of the idea of investment, the non-SCF scenario used another person, an employee in the company, who suggested an idea about a potential investment. This led us to think whether a suggestion of a colleague could have induced internalization of a goal among state-oriented individuals, and thus, caused their higher willingness to invest in a failing project. In order to verify this speculation, we used two types of scenarios with intrapersonal and interpersonal sunk costs (Olivola, 2018). The latter was supposed to induce internalization because the investor was not identical to the decision-maker. Eventually, action vs. state orientation did not moderate the effect of the type of SCF scenario and susceptibility to SCF. Our findings are not in line with previous studies suggesting that internalization affects state-oriented people in achieving goals (Kazén et al., 2003; Shi et al., 2018). A possible explanation is that the interpersonal scenarios did not induce an adequate level of internalization. This could have caused that the internalization did not play a significant role in the relationship between action vs. state orientation and susceptibility to SCF. 


\section{Limitations and Implications for Future Research}

Even though we aimed to improve the conditions of the van Putten et al. (2010) study, our study still has several limitations. Despite the greater sample size, the snowball method of collecting data has confirmed the known fact that women are substantially more willing to participate in research than men. Therefore, making any general conclusions about gender differences could be misleading.

We also found out that the car and concert scenarios did not correlate; thus, it seems that the two scenarios picked in pilot studies were not consistent enough. As a result, we could not work with one score. However, this inconsistency could have been caused by the contextual difference between these scenarios. Specifically, according to Roth et al. (2014), there are two types of sunk cost scenarios utilization and progress decisions. In the utilization decisions, all the resources have already been invested, and decision-makers have to decide whether they utilize what they have already "purchased". In our case, the utilization decision was the concert scenario. In the progress scenarios, only a part of the resources has been invested, and thus, decision-makers deal with a dilemma of whether they should invest further resources to utilize potential benefits. The car scenario represented this type of decision in our study. Since the effect of moderators of SCF may differ in utilization- and progress-decision SCF scenarios, we want to draw attention to this often neglected information for the sake of further research (Roth et al., 2014).

Moreover, although SCF is a widely studied phenomenon, various findings of individual or gender differences are inconsistent. Our results show no support for the action vs. state orientation or gender to be predictors of susceptibility to SCF. Yet, we still suggest that further investigation of these relationships is desired. First, state-oriented individuals were more willing to continue investing in the SCF scenario and less willing to invest in the nonSCF scenario in the study of van Putten et al. (2010). We pondered that their behavior could be explained by reluctance to change. Therefore, we believe that future research on the relationship between action vs. state orientation and susceptibility to SCF should include a direct measure of a reluctance to change. Second, as we already stated, van Putten et al. (2010) concluded that the reason why state-oriented participants were more susceptible to SCF in their study might lie in their greater tendency to ruminate. Unfortunately, we have not controlled directly for the level of rumination among participants. Thus, we might have missed an important clue about a mechanism that underlies susceptibility to SCF. Future research could shed more light on this matter by including direct measures of ruminative tendencies.

Despite the outlined limitations, we believe that our conceptual replication has contributed to the knowledge about individual differences in SCF and provided inspiration for further research. Our findings also highlight the importance of replication studies in psychology because a replication crisis seems to be an ongoing and substantial problem. Eventually, as it appears, action vs. state orientation does not really matter in the susceptibility to SCF. On the other hand, further research can reveal that other individual differences such as rumination or reluctance to change could affect this cognitive bias.

\section{Acknowledgement}

The authors would like to thank Veronika Kollerová for her great help with the research. We also thank both reviewers for their con- 
structive comments and ideas. The study was supported by the Slovak Research and Development Agency as part of the research project APVV-16-0153: Cognitive failures - individual predictors and intervention possibilities.

\section{Authors' ORCID \\ Miroslava Galasová \\ https://orcid.org/0000-0001-8491-8254 \\ Matúš Grežo \\ https://orcid.org/0000-0002-3537-2862}

\section{References}

Arkes, H. R., \& Blumer, C. (1985). The psychology of sunk cost. Organizational Behavior and Human Decision Processes, 35(1), 124-140. https://doi. org/10.1016/0749-5978(85)90049-4

Bavolar, J. (2013). Validation of the adult decision-making competence in Slovak students. Judgment and Decision Making, 8(3), 386-392. http://journal.sjdm.org/13/13213/idm13213. $\underline{\mathrm{html}}$

Bruine de Bruin, W., Strough, J., \& Parker, A. M. (2014). Getting older isn't all that bad: Better decisions and coping when facing 'sunk costs.' Psychology and Aging, 29(3), 642-647. https:// doi.org/10.1037/a0036308

Button, K., loannidis, J., Mokrysz, C., Nosek, B. A., Flint, J., Robinson, E. S. J., \& Munafò, M. R. (2013). Power failure: Why small sample size undermines the reliability of neuroscience. $\mathrm{Na}$ ture Reviews Neuroscience, 14, 365-376. https:// doi.org/10.1038/nrn3475

Diefendorff, J. M., Hall, R. J., Lord, R. G., \& Strean, M. L. (2000). Action-state orientation: Construct validity of a revised measure and its relationship to work-related variables. Journal of $A p$ plied Psychology, 85(2), 250-263. https://doi. org/10.1037/0021-9010.85.2.250

Falchetta, G. (2015). The sunk cost fallacy: A literature review and an empirical test [Unpublished bachelor thesis]. School of Economics and Management, Free University of Bozen-Bolzano. https://doi. org/10.13140/RG.2.2.25171.12322

Fujino, J., Fujimoto, S., Kodaka, F., Camerer, C., Kawada, R., Tsurumi, K., Tei, S., Isobe, M., Miya- ta, J., Sugihara, G., Yamada, M., Fukuyama, H., Murai, T., \& Takahashi, H. (2016). Neural mechanisms and personality correlates of the sunk cost effect. Scientific Reports, 6: 33171. https://doi. org/10.1038/srep33171

Hayes, A., \& Rockwood, N. (2017). Regression-based statistical mediation and moderation analysis in clinical research: Observations, recommendations, and implementation. Behaviour Research and Therapy, 98, 39-57. https://doi.org/10.1016/i.brat.2016.11.001

Johnson, D., \& Whisman, M. (2013). Gender differences in rumination: A meta-analysis. Personality and Individual Differences, 55(4), 367-374. https://doi.org/10.1016/i.paid.2013.03.019

Jostmann, N. B., Koole, S. L., Van der Wulp, N. Y., \& Fockenberg, D. A. (2005). Subliminal affect regulation: The moderating role of action versus state orientation. European Psychologist, 10(3), 209-217. https://doi.org/10.1027/10169040.10.3.209

Kazén, M., Baumann, N., \& Kuhl, J. (2003). Self-infiltration vs. self-compatibility checking in dealing with unattractive tasks: The moderating influence of state vs. action orientation. Motivation and Emotion, 27(3), 157-197. https://doi.org/10.1023/A:1025043530799

Keil, M., Tan, B. C. Y., Wei, K. K., Saarinen, T., Tuunainen, V., \& Wassenaar, A. (2000). A cross-cultural study on escalation of commitment behavior in software projects. MIS Quarterly, 24(2), 299-325. https://doi.org/10.2307/3250940

Kelly, T. (2004). Sunk costs, rationality, and acting for the sake of the past. Nous, 38(1), 60-85. https:// doi.org/10.1111/i.1468-0068.2004.00462.x

Koole, S. L., \& Jostmann, N. B. (2004). Getting a grip on your feelings: Effects of action orientation and social demand on intuitive affect regulation. Journal of Personality and Social Psychology, 87(6), 974-990. https://doi.org/10.1037/0022$\underline{3514.87 .6 .974}$

Kuhl, J. (1992). A theory of self-regulation: Action versus state orientation, self-discrimination, and some applications. Applied Psychology, 41 (2), 97129. https://doi.org/10.1111/i.1464-0597.1992. tb00688.x

Kuhl, J. (1994). Action versus state orientation: Psychometric properties of the Action Control Scale (ACS-90). In J. Kuhl \& J. Beckmann (Eds.), Volition and personality: Action versus state orientation (pp. 47-59). Seattle, WA: Hogrefe \& Huber. 
Kuhl, J. (2000). The volitional basis of personality systems interaction theory: Applications in learning and treatment contexts. International Journal of Educational Research, 33(7-8), 665-703. https:// doi.org/10.1016/S0883-0355(00)00045-8

Kuhl, J., \& Beckmann, J. (1994). Alienation: Ignoring one's preferences. In J. Kuhl \& J. Beckmann (Eds.), Volition and personality: Action versus state orientation (pp. 375-389). Seattle, WA: Hogrefe \& Huber.

Laing, G. K. (2000). Decision making under sunk costs [Unpublished doctoral dissertation]. School of Accounting and Finance, University of Wollongong.

Liang, S., \& Zou, Y. (2018). Validation of adult decision-making competence in Chinese college students. Judgment and Decision Making, 13(4), 393400. http://journal.sjdm.org/18/18423/jdm18423. $\underline{\mathrm{html}}$

Olivola, C. Y. (2018). The interpersonal sunk-cost effect. Psychological Science, 29(7), 1-12. https:// doi.org/10.1177/0956797617752641

Preacher, K. J., Hayes, A. F. (2004). SPSS and SAS procedures for estimating indirect effects in simple mediation models. Behavior Research Methods, Instruments, \& Computers, 36(4), 717-731. https://doi.org/10.3758/BF03206553

Richardson, J. A. (2011). Investigating how resource and situation type influence the sunk-cost fallacy. Syracuse University Honors Program Capstone Projects. 296. https://surface.syr.edu/honors capstone/296

Ronayne, D., Sgroi, D., \& Tuckwell, A. (2020). Evaluating the sunk cost effect. CAGE working paper no. 475. Competitive Advantage in the Global Economy (CAGE).

Roth, S., Robbert, T., \& Straus, L. (2014). On the sunk-cost effect in economic decision-making: A meta-analytic review. Business Research, 8(1), 99138. https://doi.org/10.1007/s40685-014-0014-8

Schulz, A. K. D., \& Cheng, M. M. (2002). Persistence in capital budgeting reinvestment decisions-personal responsibility antecedent and information asymmetry moderator: A note. Accounting \& Finance, 42(1), 73-86. https://doi.org/10.1111/1467-629X.00004 Shi, R., Zhang, S., Miao, D., Zhang, Q., Wang, Z., \& Zhang, Y. (2018). Individual difference in goal motives and goal content: The role of action and state orientation. Journal of Pacific Rim Psychology, 12(e20), 1-10. https://doi.org/10.1017/ prp. 2018.8

Staw, B. M. (1976). Knee-deep in the big muddy: A study of escalating commitment to a chosen course of action. Organizational Behavior and Human Performance, 16(1), 27-44. http://doi. org/10.1016/0030-5073(76)90005-2

Tait, V., \& Miller, H. (2019). Loss aversion as a potential factor in the sunk-cost fallacy. International Journal of Psychological Research, 12(2), 8-16. https://doi.org/10.21500/20112084.3951 van Putten, M., Zeelenberg, M., \& van Dijk, E. (2010). Who throws good money after bad? Action vs. state orientation moderates the sunk cost fallacy. Judgment and Decision Making, 5(1), 33-36. https://psycnet.apa.org/record/2010-04180-004

Wolf, B., Herrmann, M., \& Brandstätter, V. (2018). Self-efficacy vs. action orientation: Comparing and contrasting two determinants of goal setting and goal striving. Journal of Research in Personality, 73, 35-45. https://doi.org/10.1016/i. irp.2017.11.001

Yoder, C., Mancha, R., \& Agrawal, N. (2014). Culture-related factors affect sunk cost bias. Behavioral Development Bulletin, 19(4), 105-118. http://dx.doi.org/10.1037/h0101086 